Proc. Indian Acad. Sci. (Earth Planet. Sci.) Vol. 91, No. 1, March 1982, pp. 15-19.

(c) Printed in India.

\title{
A search for correlation between seismicity and radon anomaly in hot springs
}

\author{
B S AMIN and RAMA \\ Tata Institute of Fundamental Research, Homi Bhabha Road, Bombay 400 005, India \\ MS received 15 May 1981; revised 1 October 1981

\begin{abstract}
Measurements of radon contents of the exholved gas emanating from several hot water springs along the Western Coast of India are reported here.

Concentration of radon in gas phase of individual springs varied in general, directly with the surface temperature of the water emerging from the respective springs, and showed little variation with time.

Radon measurements were carried out continuously for about two years at two hot springs located at Ganeshpuri and Sathivali in the coastal area of Northern Maharashtra. The distant tremors did not cause any variation in the radon content. There was no marked local seismic activity during the period of observations, and the levels of radon stayed essentially constant.

The measurements were also carried out at a hot spring in Assam, for about 8 months. These also did not show any significant variation; this period too lacked any marked local seismicity.
\end{abstract}

Keywords. Radon anomaly; hot springs; gas phase; earthquake prediction.

\section{Introdaction}

In recent years earthquake prediction has gained a great scientific impetus. Specific predictions are based upon the occurrence of anomalies in certain geophysical parameters before the earthquake. These anomalies, considered as 'precursors' to an earthquake, alter rather quickly just before an earthquake, thereby making prediction possible. The anomalies in the electrical conductivity, radon content, tilt, and $p$-wave/s-wave velocity ratios are some of the commonly considered precursors to an earthquake. Precursors in general have two forms: bay-form and peaked-form. Bay-form precursors recover to their normal level before an earthquake whereas peaked-form show maximum level at the time of earthquake and recover to the normal levels afterwards. The bay-form precursor is obviously more useful for earthquake prediction.

Radon, with a half-life of 3.8 days, is produced by the decay of radium, which is usually present in small amounts in all rocks and soils. Being gaseous, it diffuses out of rocks and soils into ground waters, hot springs and the atmosphere. Radon content is observed to be anomalously larger near active faults, and to show temporal variations related to local seismic activity (King 1978).

Ulomov and Mavashev (1971) reported an abnormal increase of radon concentration in ground waters prior to the Tashkent earthquake of April 26, 1966.

Although, some measurements of radon in ground waters (Moore et al 1977; Noguchi and Wakita 1977), in shallow dry holes in San Andreas Fault (King 1978), 
at hard rock sites in the Southern California range (Melvin et al 1978), and in thermal springs and wells in Southern California (Craig et al 1975) have been reported, the application of radon anomaly as a precursor of an earthquake is yet to be established.

We undertook a study of radon content in a few hot springs located in the Western India in 1966. The initial effort of our programme involved a general survey of the radon levels in the hot springs (approximate locations are shown in figure 1). Subsequently, we set up a few stations to measure radon continuously to find out if there exists a correlation between the radon concentration and the seismic activity. In this note we present the results obtained in the preliminary survey as well as at the continuous monitoring stations.

\section{Experimental}

An inverted glass funnel is placed on the rock fracture where the hot water gushes out along with gas bubbles. The gas is channelled into a stainless steel chamber of about $100 \mathrm{ml}$ volume, the inner walls of which are coated with $\mathrm{ZnS}(\mathrm{Ag})$ to function as a scintillation counter. The chamber is viewed by a photo-multiplier tube whose output is insensitive to variation in ambient temperature. The monitoring system mainly consists of the scintillation chamber, photomultiplier tube and electronic recording unit; schematically shown in figure 2 . The gas flow is monitored by connecting the outlet of the chamber into a bubbler.

The radioactivity of radon is assayed by counting the three alphas produced by the decay of ${ }^{222} \mathrm{Rn}$ and its daughters ${ }^{218} \mathrm{Po}$ and ${ }^{214} \mathrm{Po}$ in the scintillation counter. The gas brings radon, stripped of its daughters, into the chamber. However, soon a radioactive equilibrium between radon and its short-lived decay products is established.

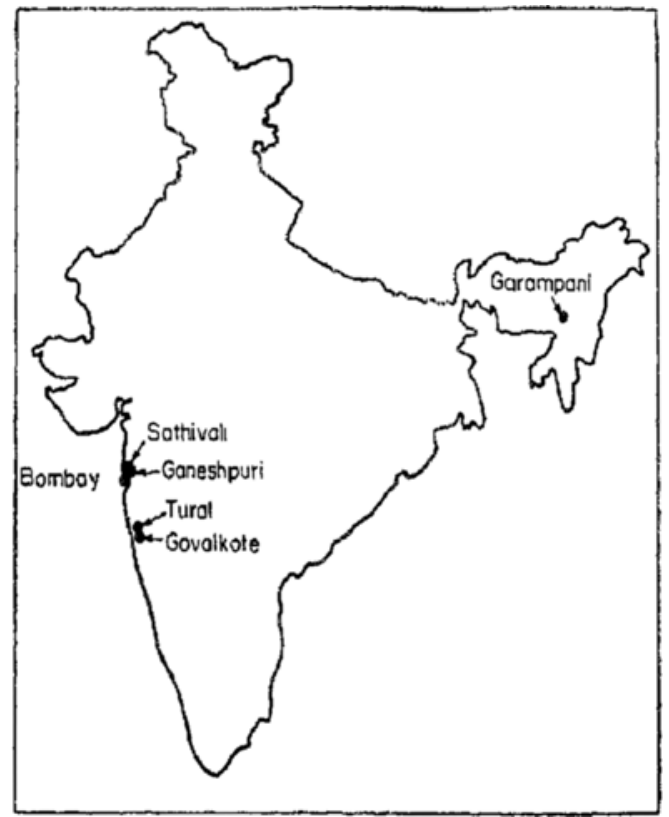

Figure 1. Locations of hot springs where radon measurements were made. 


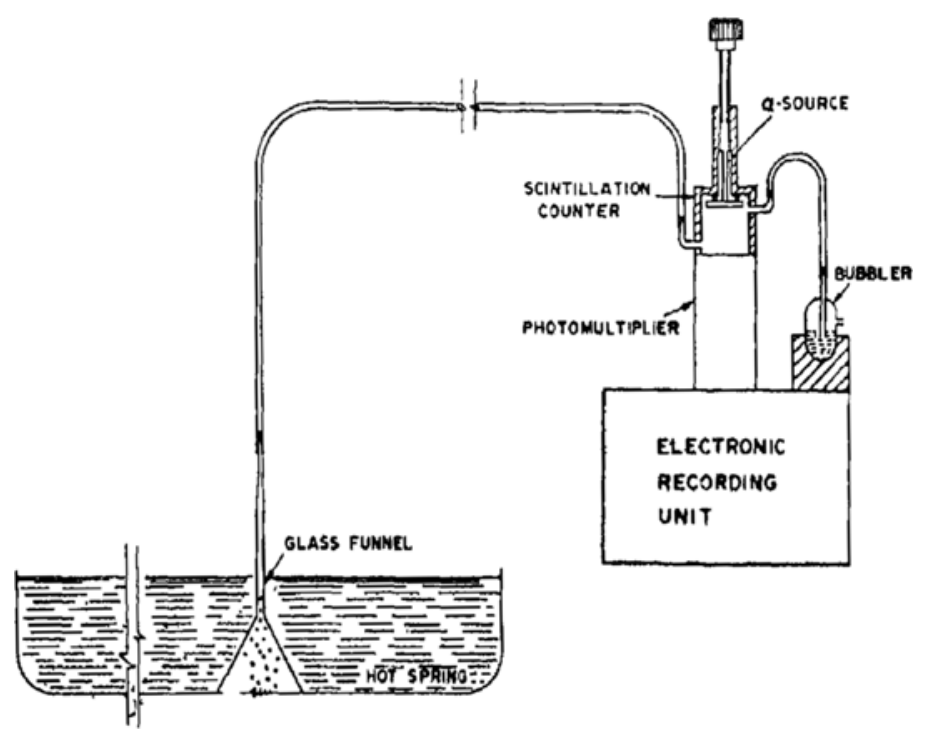

Figure 2. Radon monitoring unit.

As expected, counting rate was found to be independent of gas filow rate, within wide limits. It depends only on the amount of gas in the chamber and its radon content. A periodic check on the stability of the detection system was done by counting alphas from ${ }^{241} \mathrm{Am}$ source which was deposited on a stainless steel rod that could be introduced into the scintillation counter from above.

Measurements of radon were carried out continuously at two field stations. Ganeshpuri and Sathivali (both in the Western region) for about two years during 1975-77. At these stations (as well as for the field survey), the equipment was operated with batteries, due to non-availability of mains supply at the hot spring sites. Later, a station was set up at Garampani (Assam) where the hot spring is situated in the limestone formation in the North-Eastern region of India, which is known to be seismically active. The measurements of radon were carried out at Garampani for nearly a year, 1978-79, using a halogen filled Geiger counter as $\gamma$-ray detector, housed inside a chamber of about $200 \mathrm{ml}$ volume. A check on the stability of detection system was kept by counting periodically a standard source of ${ }^{137} \mathrm{Cs}$. The detection system was free from any susceptibility to variations in ambient temperature. An automated printing device was used for recording the observations; mains supply was available here. Temperature of the water was also measured intermittently at all the sites.

\section{Results and Discussion}

Concentration of radon in gas-phase of various hot springs are given in table 1. The hot springs in the Western region of India ate located approximately parallel to the West Coast, mostly on the banks of rivulets at the foot hills of Western Ghats. The region is part of Deccan traps of late cretaceous period. The steep slope of the traps towards the Arabian Sea has led some people to suspect a deep seated fault along the 
Table 1. Radon contents of gas phase in hot springs

\begin{tabular}{|c|c|c|c|c|}
\hline \multicolumn{2}{|c|}{ lccation } & \multirow{2}{*}{ Formation } & \multirow{2}{*}{$\begin{array}{c}\text { Water } \\
\text { temperature } \\
\left({ }^{\circ} \mathrm{C}\right)\end{array}$} & \multirow{2}{*}{$\begin{array}{c}{ }^{222} \mathrm{Rn} \text { concentra- } \\
\text { tion } \\
\text { (dpm/c.c. gas) }\end{array}$} \\
\hline Region & Name of the spring & & & \\
\hline Ganeshpuri & Ramkund & Basalt & 55 & 0.52 \\
\hline$"$ & Sitakund & $"$ & 50 & 0.38 \\
\hline , & Anusuyakund & $"$ & 48 & $0 \cdot 23$ \\
\hline, & Kothayalakund & $"$ & 49 & 0.28 \\
\hline Sathivali & Sathivali Temple & $"$ & 54 & 0.63 \\
\hline Konkan & Tural & $"$ & 61 & $4 \cdot 3$ \\
\hline$"$ & Govalkote & " & - & 6.5 \\
\hline Assam & Garampani & Limestone & 50 & $115 \cdot 0$ \\
\hline
\end{tabular}

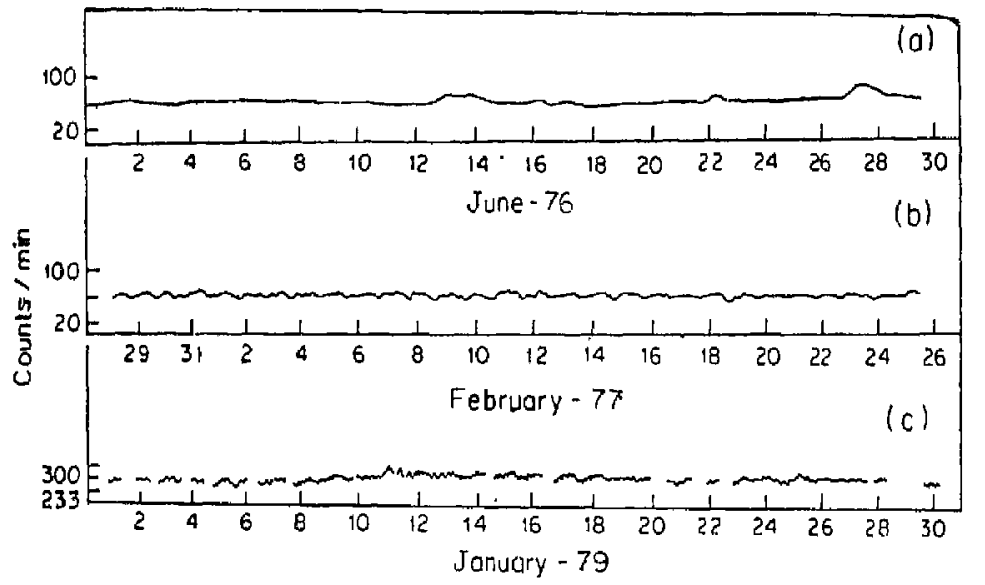

Figure 3. Concentration of radon in the gas evolved from hot springs; (A) Ganeshpuri (Mahatashtra), (B) Sathivali (Maharashtra) and (C) Garampani (Assam).

Coastal region. It is observed that the radon concentration in the gas phase of these springs varies with the surface temperature of water emerging from these springs.

The hot spring in the North-Eastern region of India at Garampani is located on a fault which is traceable for a distance of nearly $8 \mathrm{~km}$ along the right bank of Kopili river. Various rock formations in the region belong to Archaeans and Tertiary sedimentaries. Radon concentration observed at Garampani is two orders of magnitude higher, though the surface temperature of water is similar to that in the Western region.

The results of the continuous monitoring of radon at Ganeshpuri, Sathivali and Garampani hot springs, carried out for about a year at each station, indicate no significant variation in concentration of radon. The observed concentration of radon (counts per minute) at the three field stations is plotted for a period of one month each, as a typical observation out of a year long measurement at each station(figure 3). The gaps in observational data in part (C) of figure 3 are due to frequent mains failures. The level of radon concentration at all the three stations has stayed quite constant (within a few per cent) in the absence of any marked local seismic activity. 
Variations to the extent of $1-2 \%$ can arise due to variations in the quantity of gas in the chamber resulting from changes in ambient temperature and pressure.

We intend to continue measurements at a number of locations in North-Eastern region, a seismically active area. We further consider it necessary to monitor radon in a vehicle (like water in hot springs or gas in oil wells) which brings information from deep seated areas and is not affected by atmospheric parameters.

\section{Acknowledgements}

The authors thank Dr A S Tamliane and Mr O B Fernandes for help in making measurements. Mr O B Fernandes fabricated the electronic recording unit. They are grateful to Major J M Kothavala for his cooperation in carrying out measurements at Ganeshpuri. The authors also acknowledge with grateful thanks the help received from NEEPCO and North-Eastern Hill University to carry out the measurements in the North-Eastern region. In the initial phases of the experiment (about 1965-70), the valuable association of Dr G Rajagopalan and Mr P D'Souza is gratefully acknowledged.

\section{References}

Craig H, Lupton J E, Chung Y and Horowitz R M 1975 SIO Tech. Rep. No. 1·1 King Chi-Y 1978 Nature (London) 271516

Melvin J D, Shapiro M H and Copping N A 1978 Nucl. Instrum. Methods 153239

Moore W S, Chiang J H, Talwani P and Stevenson D A 1977 EOS, Trans. Am. Geophys. Union 58 434

Noguchi M and Wakita H 1977 J. Geophys. Res. 821353

Ulmov V L and Mavashev B Z 1971 Akad. Nauk Usbek SSR FAN 188 